Hoogerduijn, J.G., Schuurmans, M.J., Korevaar, J.C., Buurman, B.M., Rooij, S.E. de.

\begin{tabular}{|l|l|}
\hline $\begin{array}{l}\text { Postprint } \\
\text { Version }\end{array}$ & 1.0 \\
\hline $\begin{array}{l}\text { Journal website } \\
\text { Pubmed link }\end{array}$ & http://onlinelibrary.wiley.com/doi/10.1111/j.1365-2702.2009.03035.x/abstract \\
\hline DOI & http://www.ncbi.nlm.nih.gov/pubmed/20345834 \\
\hline
\end{tabular}

This is a NIVEL certified Post Print, more info at http://www.nivel.eu

\title{
Identification of older hospitalised patients at risk for functional decline, a study to compare the predictive values of three screening instruments
}

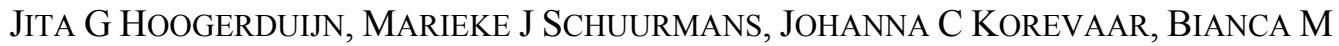 \\ BUURMAN, SOPHIA E DE ROOIJ
}

Authors:Jita G Hoogerduijn, MScN, RN, PhD Candidate, Research Group Care for the Chronically III, Faculty of Health Care, Hogeschool Utrecht, University of Applied Science; Marieke J Schuurmans, PhD, RN, Professor, Research Group Care for the Chronically III, Faculty of Health Care, Hogeschool Utrecht, University of Applied Science, Utrecht, The Netherlands; Johanna C Korevaar, PhD, Senior Epidemiologist, Department of Clinical Epidemiology, Biostatistics and Bioinformatics, Academic Medical Centre; Bianca M Buurman, MScN, RN, PhD Candidate, Department of Internal Medicine and Geriatrics, Academic Medical Centre; Sophia E de Rooij, PhD, MD, Associate Professor, Department of Internal Medicine and Geriatrics, Academic Medical Centre, Amsterdam, The Netherlands

\begin{abstract}
Aims and objectives. To establish a screening instrument for identifying older hospitalised patients at risk for functional decline by comparing the predictive values of three screening instruments: identification of seniors at risk, care complexity prediction instrument and hospital admission risk profile.

Background. After being hospitalised, 30-60\% of older patients experience a decline in functioning, resulting in a decreased quality of life and autonomy.

Design. A prospective cohort study.

Methods. Included were patients, aged 65 years and older, acutely admitted to a general internal ward of a university teaching hospital. Within 48 hours after hospital admission, baseline data were completed - demographic, cognitive, social and pre-admission functional status and the screening instruments. Three months after discharge, functional status was measured by telephone interview. The Katz index was used to measure functional status (six activities). Functional decline was defined as a decline of at least one point on the Katz index at three months after discharge compared to pre-admission state.

Results. Included were 177 patients; mean age was 77.6 years and $51.7 \%$ were male. Functional decline was found in $27 \cdot 8 \%$ of all patients. Sensitivity, specificity and area under receiver operating curve for identification of seniors at risk (ISAR) were 93, 39\% and $0 \cdot 67$, respectively. The corresponding results
\end{abstract}


Hoogerduijn, J.G., Schuurmans, M.J., Korevaar, J.C., Buurman, B.M., Rooij, S.E. de. Identification of older hospitalised patients at risk for functional decline, a study to compare the predictive values of three screening instruments. Journal of Clinical Nursing: 2010, 19(9/10) 7 1219-1225

for the care complexity prediction instrument (COMPRI) were 70, 62\% and 0.69 and for the hospital admission risk profile (HARP) $21,89 \%$ and $0 \cdot 56$.

Conclusion. The discriminative values of both identification of seniors at risk and care complexity prediction instrument are fair. Hospital admission risk profile shows the poorest results. Identification of seniors at risk shows the best ability to predict those patients at risk for functional decline and seems to be the easiest instrument in clinical practice.

Relevance to clinical practice. Identifying patients at risk for functional decline is a first step in prevention, followed by geriatric assessment and targeted interventions. Studying the validity of existing instruments is necessary before implementation in clinical practice.

\section{INTRODUCTION}

Functional decline is a common and serious problem in hospitalised older patients. After being acutely hospitalised, 30-60\% of older patients experience a decline in functioning (Sager et al. 1996a, Mahoney et al. 1999, McVey et al. 1989). This functional decline is usually defined as a new loss of independence in self-care activities or as deterioration in self-care skills and is measured on an activity of daily living (ADL) scale (e.g. bathing, dressing, transferring from bed to chair, using the toilet) and/or an instrumental activities of daily living (IADL) scale (e.g. shopping, housekeeping, preparing meals, taking medications, handling finances, using public transport) (Fortinsky et al. 1999, Hebert et al. 1999). Functional decline results in a change of health-related quality of life and in decreased autonomy and is associated with increased risks of hospital readmission, nursing home placement and mortality (Alarcon et al. 1999, Satish et al. 1996, Carlson et al. 1998, Covinsky et al. 1997, Ingold et al. 2000, Fortinsky et al. 1999), so it leads to increased health care and personal costs.

Functional decline is not strictly related to the medical problem that caused admission and is not automatically recovered when the medical problem is treated. Several factors play a role in the occurrence of functional decline, such as the condition of the patient before admission, co-morbidity, iatrogenic effects of the treatment and effects of bed rest (Hoenig \& Rubenstein 1991, Harper \& Lyles 1988, Mobily \& Skemp Kelley 1991, Sager \& Rudberg 1998). The most significant predictors of functional decline are age, lower functional status before hospital admission, impaired cognitive status, depression and prolonged length of hospital stay (Hoogerduijn et al. 2007).

Based on the current literature, some screening instruments that might identify hospitalised older patients at risk for functional decline are available: the identification of seniors at risk (ISAR) (McCusker et al. 1999, Dendukuri et al. 2004), the care complexity prediction instrument (COMPRI) (Huyse et al. 2001, de Jonge et al. 2001a,b) and the hospital admission risk profile (HARP) (Sager et al. 1996b). These instruments were developed and validated in different populations and are designed to predict functional decline or outcomes related to functional decline, such as complex care needs, poor discharge health status and extended length of stay. Their predictive values have not been compared in patients acutely admitted to the general internal ward of the hospital.

Therefore, the aim of this study is to establish a screening instrument for identifying older patients, acutely admitted to the general internal ward of the hospital, at risk for functional decline by comparing the predictive values of the three screening instruments. 
Hoogerduijn, J.G., Schuurmans, M.J., Korevaar, J.C., Buurman, B.M., Rooij, S.E. de. Identification of older hospitalised patients at risk for functional decline, a study to compare the predictive values of three screening instruments. Journal of Clinical Nursing: 2010, 19(9/10) 1219-1225

\section{METHODS}

\section{Study population}

All patients 65 years and older acutely admitted to the Department of Internal Medicine of the Academic Medical Centre (AMC), a 1024-bed university teaching hospital were evaluated for eligibility. Patients were excluded from the study if they were too ill, came from another ward or were admitted from another hospital, did not stay at least 48 hours or did not speak or understand Dutch.

\section{Ethical considerations}

The hospital's Medical Ethics Committee approved the study. Only patients who gave written informed consent were included in this study.

\section{Data collection}

Patients were included in the study from October 2004-November 2005. Within 48 hours after admission, all baseline data were completed by a trained research nurse who interviewed the patients. The baseline data consisted of demographic data (age, sex, living and social situation), cognitive status, premorbid functional status (i.e. two weeks before admission) and the three screening instruments, ISAR, COMPRI and HARP. A geriatrician completed the clinical data with the medical diagnoses. In the event of severe cognitive problems, the data were collected by interviewing the patient's proxy.

Three months after discharge, functional status was measured by telephone interview.

\section{MEASUREMENT INSTRUMENTS}

\section{Functional decline}

The Katz index of independence in activities of daily living (Katz index) was used to determine functional status, measuring bathing, dressing, toileting, transferring, continence and feeding. The index was scored per item as $0=$ independent and $1=$ dependent. The total score ranged from 0 (total independence) to 6 (total dependence). Patients were asked to rate their ADL status as it stood two weeks before hospital admission to eliminate the effects of the illness that led to that admission (Brorsson \& Asberg 1984, Weinberger et al. 1992). Functional decline was defined as a decline of at least one point on the Katz index at three months after discharge compared to the pre-admission state.

\section{Cognition}

Cognitive functioning was measured using the Mini Mental State Examination (MMSE) on a scale of 0 (poor)-30 (excellent) with a cut off $<24$ indicating cognitive impairment (Folstein et al. 1975, Tombaugh \& McIntyre 1992).

\section{The screening instruments}

The ISAR was developed to identify patients at risk for mortality, functional decline, readmission and institutionalisation, in the emergency departments (ED) of four universityaffiliated hospitals in Montreal, Canada (McCusker et al. 1999). The instrument was validated in a study including patients aged 65 years and older (development sample $n=997$, validation sample $n=676$ ). It consists of six self-report questions with yes/no responses on functional dependence: premorbid and acute change in functioning, recent hospitalisation, impaired memory and vision and polypharmacy. The items were selected on the basis of face validity, predictive value and ease of administration. The cut-off point is 2 , indicating that patients with a score $\geq 2$ are at risk of adverse health outcomes, including decrease in functional status. Sensitivity (72\%), specificity $(58 \%)$ and area under the receiver operating curve (AUC) (0.71) were fair. Moreover, the ISAR was evaluated in 2004 in two independent groups of 1122 and 520 patients with a positive result in predicting severe functional impairment, the AUC was $0 \cdot 86$ (Dendukuri et al. 2004). According to these 
Hoogerduijn, J.G., Schuurmans, M.J., Korevaar, J.C., Buurman, B.M., Rooij, S.E. de. Identification of older hospitalised patients at risk for functional decline, a study to compare the predictive values of three screening instruments. Journal of Clinical Nursing: 2010, 19(9/10) 1219-1225

authors, the ISAR is easy to use as it is a short and quick instrument that can be completed by either patients or their informants (McCusker et al. 1999, Dendukuri et al. 2004).

The COMPRI was developed to screen hospitalised patients at risk for complex care needs, poor discharge health status and an extended length of stay. This instrument was validated in two Dutch hospitals in a study including patients admitted to a general medical ward $(n=275)$. It was derived from a list of 117 potential risk factors. The items most predictive for length of stay and some other indicators for hospital-based care use were selected: doctors' and nurses' expectations about care complexity, premorbid health status and health care use (de Jonge et al. 2001a). The instrument has to be completed by three different respondents; four items are rated by the physician, three by the nurse and six by interviewing the patient. The cut-off point is 6 , indicating that a score $\geq 6$ is a patient in need of complex care. In the validation study, sensitivity (71\%), specificity $(63 \%)$ and the AUC $(0.73)$ were fair and so were the positive (70\%) and negative (64\%) predictive value (de Jonge et al. 2003, Huyse et al. 2001, de Jonge et al. 2001a,b, 2003).

The HARP was developed in six acute care hospitals in the USA $(n=827)$ as an instrument for classifying patients of 70 years and older according to their risk of developing new disabilities in SIX ADL functions (bathing, dressing, transferring, walking, toileting and eating) during hospital stay and three months after discharge. It includes 25 questions and consists of three types of variables derived from a larger study to determine the strongest predictors of functional decline: age, an abbreviated MMSE and seven ADL and IADL functions, classified as $0=$ no risk, $1=$ intermediate risk and $2=$ high risk. The cut-off points in this instrument are $<2$ (low risk), $2-3$ (intermediate risk) and $>3$ (high risk). The AUC $(0 \cdot 65)$ proved to be fair. According to the authors, the HARP can be considered an easy-touse instrument suitable for identifying patients at risk for functional decline, who could benefit from comprehensive discharge planning and specialised geriatric care (Sager et al. $\underline{1996 b})$.

\section{Measurements of predictive value}

The ability of a test to discriminate individuals with and without the outcome is evaluated using the AUC. The most important quality is the ability to predict which patient is at risk. For this reason, sensitivity and positive predictive value are key measurements. The ability to identify correctly those patients who are not at risk is also relevant so that over-treatment is precluded, and this is measured by the specificity and the negative predictive value.

\section{Statistical analysis}

Analysis was performed using spss, version 15 (Statistic Package for Social Studies, Inc. Chicago, IL, USA). For nominal variables, percentages, means and numbers were calculated to describe the population. Student's t-test, Mann-Whitney and chi-square were used to compare the included patients with the deceased and missing patients. Sensitivity, specificity, positive and negative predictive value of all three instruments were calculated, and the discriminative value was measured by the AUC. The AUC can range from 0.5 (no discrimination) $-1 \cdot 0$ (perfect discrimination) (Hanley \& McNeil 1982).

\section{RESULTS}

During the inclusion period, 245 patients were eligible for this study. Mortality rate during hospital stay and within three months after discharge was $22.0 \%(\mathrm{n}=50)$. Loss to follow up owing to difficulties in contacting the patient or the relative was $7 \cdot 3 \%(\mathrm{n}=18)$. Patients who died or were missed at follow-up were significantly older. Baseline ADL and cognition showed no significant differences. One hundred and seventy-seven patients were included in the analyses.

The baseline characteristics of the patients are presented in Table 1. Mean age was $77 \cdot 6$ years, and $51 \cdot 7 \%$ were male. At admission, almost three quarters of all patients lived independently, and a little less than half of them lived with a partner. More than one third of 
Hoogerduijn, J.G., Schuurmans, M.J., Korevaar, J.C., Buurman, B.M., Rooij, S.E. de. Identification of older hospitalised patients at risk for functional decline, a study to compare the predictive values of three screening instruments. Journal of Clinical Nursing: 2010, 19(9/10) 1219-1225

the patients were cognitively impaired (MMSE score $<24$ ). Mean length of stay was $11 \cdot 6$ days.

\section{[TABLE 1]}

The mean pre-admission ADL score of the patients was 1.0 (SD 1.4). Three months after discharge, the mean ADL score was 1.4 (SD 1.9). Two weeks before admission, 50.9\% of patients were independent in performing their ADLs. Decline in functional status was found in $27.8 \%(\mathrm{n}=47)$ of the patients. Of these, $12 \cdot 4 \%(\mathrm{n}=21)$ developed a decline of 1 point, $15 \cdot 5 \%(n=26)$ a decline $\geq 2$ points. The ADL of $15 \cdot 5 \%(n=26)$ of the patients improved 1 or more points.

The sensitivity, specificity and AUC (see Table 2 and Fig. 1) for the ISAR were 93, 39\% and 0.67 , respectively. For the COMPRI, these values were $70,62 \%$ and $0 \cdot 69$, while for the HARP three categories were calculated - low, intermediate and high risk. Sensitivity was respectively 61,40 and $21 \%$, specificity was respectively 68,81 and $89 \%$, and the AUC, $0 \cdot 65,0 \cdot 60$ and $0 \cdot 56$.

\section{[TABLE 2]}

\section{[FIGURE 1]}

\section{DISCUSSION}

In this study, the predictive value of three instruments for identifying acutely hospitalised older patients at risk for functional decline were assessed and compared. None of the instruments is strong in predicting which patient is at risk while also giving a valid indication of those patients not at risk. The overall discriminative capacity of ISAR is comparable to that of COMPRI. HARP shows the lowest AUC score. The ISAR is the most sensitive instrument and has the best negative predictive value; these are the most important measurements for identifying patients at risk for functional decline. However, specificity and positive predictive value are poor, resulting in the identification of too many patients who are not at risk as patients at risk. This may lead to inefficient care by over-treatment. COMPRI shows the best specificity and positive predictive value, although its sensitivity is less than the ISAR. In our study, the HARP shows the lowest sensitivity and the highest specificity, leading to possible underestimation of the patients who are at risk and overestimation of those who are not at risk.

Some differences from the predictive value reported in earlier studies are found, which can be explained by the different backgrounds of the instruments. The ISAR was originally developed and validated in a population of older patients visiting the ED. A possible explanation for the lower values than in the original study may lie in the use of this instrument in a hospitalised population. The population visiting an ED is mostly ambulant, and it is known (McCusker et al. 2003) that only about 35\% of ED patients are expected to be admitted to hospital. The ISAR was validated in another study, which is a positive aspect.

The difference between our COMPRI results and the original study could be explained by the fact that the original purpose of this instrument was different. It was initially developed to identify all patients at risk for the need of complex care and patients at risk for an extended length of stay. These outcomes, however, overlap functional decline (Sager et al. 1996b). In the validation study of the COMPRI, all patients admitted to a medical ward were included - not only older patients, as in our study (de Jonge et al. 2003). As patients at risk are generally older, this may have influenced the discrepancies between the validation study and our study.

Just as in our study, the psychometric qualities of the HARP were moderate in the original publication (AUC $0 \cdot 56-0 \cdot 65$ ). The investigators explained this moderate predictive ability by 
Hoogerduijn, J.G., Schuurmans, M.J., Korevaar, J.C., Buurman, B.M., Rooij, S.E. de. Identification of older hospitalised patients at risk for functional decline, a study to compare the predictive values of three screening instruments. Journal of Clinical Nursing: 2010, 19(9/10) $1219-1225$

stating that the HARP describes only patient variables. They did not include illness or nivel process of care variables, both of which may be important in developing disability in older patients. In the original validation study, patients of 70 years and older were included, which differs from our younger population (65 years and older). This could also explain the different results in the present study.

Some limitations in our study need to be addressed in relation to the findings.

First, the smaller number of patients included might have resulted in lower AUCs than in the original studies. In particular, the small number of patients who developed functional decline could have led to underestimation of the predictive qualities of all three instruments. However, this does not affect the differences between the instruments.

Second, there is no gold standard for measuring functional decline, the six ADLs of the Katz index constitute an arbitrary measurement. In all studies, different definitions of functional decline were applied. Furthermore, the Katz index score is a dichotomous scale, which does not reflect the more differentiated patient reality. This may also lead to underestimation of decline in function.

Finally, $28 \%$ of the eligible patients were not included in the follow-up owing to mortality or to difficulties in contacting the patient or relative three months after discharge. These patients were significantly older. This selective loss of patients may have led to underestimation of the group of patients suffering from functional decline after hospitalisation. This may also have influenced the predictive value of all three instruments. A further effort to refine the instrumentation to identify patients at risk for functional decline is therefore needed. In such studies, the validity and reliability of the instrument should be considered together with feasibility.

Successful implementation in clinical practice depends on acceptance of a scale by professionals. Acceptance is facilitated by applicability in daily practice, ease of use and the time it takes to administer. In none of the publications concerning ISAR, COMPRI or HARP or in this study were these aspects addressed. The ISAR is a short instrument with six questions with yes/no responses and can be administered in very little time by the ward nurses. The COMPRI consists of thirteen items of which four need to be rated by the physician, three by the nurse and six by interviewing the patient. On this basis, the ISAR seems to have the advantage for large scale implementation because of the smaller number of items and the greater ease of application.

Because the ultimate goal is prevention of functional decline, measurement of the instrumental activities of daily living (IADL) could be of interest too, not only because IADLs are important for the patient's wellbeing, but also because they could act as an earlier marker of ADL decline.

The number of older people is growing in all western countries and health care professionals are faced with an older and more vulnerable group of patients. Functional decline after hospitalisation is a serious problem, older patients themselves are aware and afraid of it, as was shown in a study by Huckstadt (2002). 'Well, everybody loses their independence when they come to the hospital' was quoted by an older patient in this study. To prevent functional decline, identification of patients at risk is an essential first step, which should be followed by a comprehensive geriatric assessment and targeted interventions in patients identified as high risk.

\section{CONCLUSION}

For both ISAR and COMPRI, the discriminative value measured by the AUC is fair. HARP showed the poorest results. Taking everything into account, ISAR shows the best ability to predict those patients at risk for functional decline and seems to be the easiest instrument in clinical practice. Therefore, further development and study of ISAR is recommended, focussed on improving the positive predictive value and specificity in the population of hospitalised older patients. 
Hoogerduijn, J.G., Schuurmans, M.J., Korevaar, J.C., Buurman, B.M., Rooij, S.E. de. Identification of older hospitalised patients at risk for functional decline, a study to compare the predictive values of three screening instruments. Journal of Clinical Nursing: 2010, 19(9/10) 1219-1225

\section{RELEVANCE TO CLINICAL PRACTICE}

Identifying patients at risk for functional decline is a first step in prevention, followed by geriatric assessment and targeted interventions. Studying the validity of existing instruments is necessary before implementation in clinical practice.

\section{ACKNOWLEDGEMENTS}

This study was financed by the Netherlands Organisation for Health Research and Development (Zon Mw).

\section{CONTRIBUTIONS}

Study design: SdR, MS, JK; data collection and analysis: SdR, JH; manuscript preparation: JH, SdR, MS, JK.

\section{REFERENCES}

Alarcon T, Barcena A, Gonzalez-Montalvo JI, Penalosa C \& Salgado A (1999) Factors predictive of outcome on admission to an acute geriatric ward. Age and Ageing 28, 429432.

Brorsson B \& Asberg KH (1984) Katz index of independence in ADL. Reliability and validity in short-term care. Scandinavian Journal of Rehabilitation Medicine. 16, 125-132.

Carlson JE, Zocchi KA, Bettencourt DM, Gambrel ML, Freeman JL, Zhang D \& Goodwin JS (1998) Measuring frailty in the hospitalized elderly: concept of functional homeostasis. American Journal of Physical Medicine \& Rehabilitation. 77, 252-257.

Covinsky KE, Justice AC, Rosenthal GE, Palmer RM \& Landefeld CS (1997) Measuring prognosis and case mix in hospitalized elders. The importance of functional status. Journal of General Internal Medicine. 12, 203-208.

Dendukuri N, McCusker J \& Belzile E (2004) The identification of seniors at risk screening tool: further evidence of concurrent and predictive validity. Journal of the American Geriatrics Society 52, 290-296.

Direct Link:

Folstein MF, Folstein SE \& McHugh PR (1975) "Mini-mental state". A practical method for grading the cognitive state of patients for the clinician. Journal of Psychiatric Research 12 , 189-198.

Fortinsky RH, Covinsky KE, Palmer RM \& Landefeld CS (1999) Effects of functional status changes before and during hospitalization on nursing home admission of older adults. The journals of Gerontology. Series A, Biological sciences and Medical Sciences 54, M521M526.

Hanley JA \& McNeil BJ (1982) The meaning and use of the area under a receiver operating characteristic (ROC) curve. Radiology 143, 29-36.

Harper CM \& Lyles YM (1988) Physiology and complications of bed rest. Journal of the American Geriatrics Society 36, 1047-1054.

Hebert R, Brayne C \& Spiegelhalter D (1999) Factors associated with functional decline and improvement in a very elderly community-dwelling population. American Journal of Epidemiology 150, 501-510.

Hoenig HM \& Rubenstein LZ (1991) Hospital-associated deconditioning and dysfunction. Journal of the American Geriatrics Society 39, 220-222.

Hoogerduijn JG, Schuurmans MJ, Duijnstee MS, De Rooij SE \& Grypdonck MF (2007) A systematic review of predictors and screening instruments to identify older hospitalized patients at risk for functional decline. Journal of Clinical Nursing 16, 46-57.

Direct Link:

Huckstadt AA (2002) The experience of hospitalised elderly patients. Journal of Gerontological Nursing 28, 25-29.

Huyse FJ, De Jonge P, Slaets JP, Herzog T, Lobo A, Lyons JS, Opmeer BC, Stein B, Arolt V, Balogh N, Cardoso G, Fink P \& Rigatelli M (2001) COMPRI - an instrument to detect patients with complex care needs: results from a European study. Psychosomatics 42, 222-228. 
Hoogerduijn, J.G., Schuurmans, M.J., Korevaar, J.C., Buurman, B.M., Rooij, S.E. de. Identification of older hospitalised patients at risk for functional decline, a study to compare the predictive values of three screening instruments. Journal of Clinical Nursing: 2010, 19(9/10) $1219-1225$

Ingold BB, Yersin B, Wietlisbach V, Burckhardt P, Bumand B \& Bula CJ (2000)

Characteristics associated with inappropriate hospital use in elderly patients admitted to a general internal medicine service. Aging (Milan, Italy) 12, 430-438.

De Jonge P, Huyse FJ, Herzog T, Lobo A, Slaets JP, Lyons JS, Opmeer BC, Stein B, Arolt V, Balogh N, Cardoso G, Fink P \& Rigatelli M (2001a) Risk factors for complex care needs in general medical inpatients: results from a European study. Psychosomatics 42, 213221.

De Jonge P, Huyse FJ, Slaets JP, Herzog T, Lobo A, Lyons JS, Opmeer BC, Stein B, Arolt V, Balogh N, Cardoso G, Fink P, Rigatelli M, Van Dijck R \& Mellenbergh GJ (2001b) Care complexity in the general hospital: results from a European study. Psychosomatics 42, 204-212.

De Jonge P, Bauer I, Huyse FJ \& Latour CH (2003) Medical inpatients at risk of extended hospital stay and poor discharge health status: detection with COMPRI and INTERMED. Psychosomatic Medicine 65, 534-541.

Mahoney JE, Sager MA \& Jalaluddin M (1999) Use of an ambulation assistive device predicts functional decline associated with hospitalization. The Journals of Gerontology. Series A, Biological Sciences and Medical Sciences 54, M83-M88.

McCusker J, Bellavance F, Cardin S, Trepanier S, Verdon J \& Ardman O (1999) Detection of older people at increased risk of adverse health outcomes after an emergency visit: the ISAR screening tool. Journal of the American Geriatrics Society 47, 1229-1237.

McCusker J, Dendukuri N, Tousignant P, Verdon J, Poulin DC \& Belzile E (2003) Rapid twostage emergency department intervention for seniors: impact on continuity of care.

Academic Emergency Medicine 10, 233-243.

McVey LJ, Becker PM, Saltz CC, Feussner JR \& Cohen HJ (1989) Effect of a geriatric consultation team on functional status of elderly hospitalized patients. A randomized, controlled clinical trial. Annals of Internal Medicine 110, 79-84.

Mobily PR \& Skemp Kelley LS (1991) latrogenesis in the elderly. Factors of immobility. Journal of Gerontological Nursing 17, 5-11.

Sager MA \& Rudberg MA (1998) Functional decline associated with hospitalization for acute illness. Clinics in Geriatric Medicine 14, 669-679.

Sager MA, Franke T, Inouye SK, Landefeld CS, Morgan TM, Rudberg MA, Sebens H \& Winograd CH (1996a) Functional outcomes of acute medical illness and hospitalization in older persons. Archives of Internal Medicine 156, 645-652.

Sager MA, Rudberg MA, Jalaluddin M, Franke T, Inouye SK, Landefeld CS, Siebens H \& Winograd CH (1996b) Hospital admission risk profile (HARP): identifying older patients at risk for functional decline following acute medical illness and hospitalization. Journal of the American Geriatrics Society 44, 251-257.

Satish S, Winograd CH, Chavez C \& Bloch DA (1996) Geriatric targeting criteria as predictors of survival and health care utilization. Journal of the American Geriatrics Society 44, 914-921.

Tombaugh TN \& Mclntyre NJ (1992) The mini-mental state examination: a comprehensive review. Journal of the American Geriatrics Society 40, 922-935.

amsa GP, Schmader K, Greenberg SM, Carr DB \& Wildman DS (1992) Comparing proxy and patients' perceptions of patients' functional status: results from an outpatient geriatric clinic. Journal of the American Geriatrics Society 40, 585-588. 
Hoogerduijn, J.G., Schuurmans, M.J., Korevaar, J.C., Buurman, B.M., Rooij, S.E. de. Identification of older hospitalised patients at risk for functional decline, a study to compare the predictive values of three screening instruments. Journal of Clinical Nursing: 2010, 19(9/19) 1219-1225

\section{TABLES AND FIGURE}

\section{Table 1}

Table 1 Demographic and dinical characteristics $(n=177)$

\begin{tabular}{|c|c|}
\hline$A_{\text {ser }}$ (years), mean (SD) & $77 \cdot 6(7-9)$ \\
\hline Sex, mak \% $(n)$ & $517(91)$ \\
\hline \multicolumn{2}{|l|}{ Living situation at admission $\%(n)$} \\
\hline Independert & $740(128)$ \\
\hline Nursing horne & $3: 5(6)$ \\
\hline Partly independent & $220(38)$ \\
\hline Eke & $0-6(1)$ \\
\hline \multicolumn{2}{|l|}{ Social situation at admission $\%(n)$} \\
\hline Living alone & $12 \cdot 9(22)$ \\
\hline Living with a partner & $46 \cdot 2(79)$ \\
\hline Living a lone after divorce or as a widow & $409(70)$ \\
\hline Cognitive-impaired $\%(n)$ & $380(65)$ \\
\hline Premorbid ADL score, mean (SD) & $10(1-4)$ \\
\hline Premorbid independent in ADL. \% (n) & 509 (89) \\
\hline ADL decline three month after discharge $\%(n)$ & $27-8(47)$ \\
\hline Decline of 1 point & $124(21)$ \\
\hline Dedine $\geq 2$ points & $15.5(26)$ \\
\hline Improved $A D L \geq 1$ poirt & $15.5(26)$ \\
\hline \multicolumn{2}{|l|}{ Medical diagnessis (\%) } \\
\hline Infectious disease & 53 \\
\hline Malignancy & 6 \\
\hline Gastrointestinal bleeding & 3 \\
\hline Water and electrol yte disturbances & 19 \\
\hline Other & 19 \\
\hline Length of stay (days), mean (SD) & $11-6(11-8)$ \\
\hline Deceased $\%(n)$ & $220(50)$ \\
\hline
\end{tabular}

Table 2

Table 2 The predictive values of three screening instruments predicting functional decline in older howpitalised patients scutely admitted to an intemal ward

\begin{tabular}{llllll}
\hline & $\begin{array}{l}\text { Sernitivity } \\
(\%)\end{array}$ & $\begin{array}{l}\text { Specificity } \\
(\%)\end{array}$ & $\begin{array}{l}\text { Positive predictive } \\
\text { value }(\%)\end{array}$ & $\begin{array}{l}\text { Negative predictive } \\
\text { value (\%) }\end{array}$ & $\begin{array}{l}\text { Area under the curve } \\
(95 \% \text { confidence interval) }\end{array}$ \\
\hline $\begin{array}{l}\text { ISAR } \\
\text { COMPRI }\end{array}$ & $92-9$ & 393 & 364 & $93-6$ & $0-67(0-58-0-77)$ \\
HARP & $70-2$ & 620 & 418 & $84-3$ & $0-69(0-59-0-79)$ \\
Low risk & $60-5$ & 684 & 390 & $83-9$ & $0-65(0-54-0-75)$ \\
Intermediate risk & $39-5$ & 807 & 405 & $80-0$ & $0-60(0-49-0-71)$ \\
High risk & $21-1$ & 886 & 381 & $77-1$ & $0-56(0-45-0-77)$ \\
\hline
\end{tabular}

COMPRI, the care complexity prediction instrument; HARP, the hospital admission risk profile; ISAR, the identification of senions at risk.

\section{Figure 1}

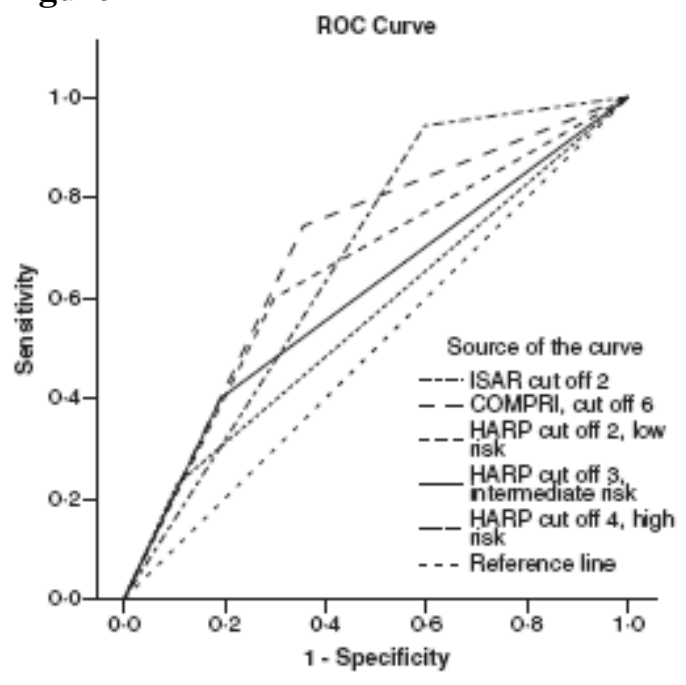

Diagonal segments are produced by ties. 